\title{
IbM KELOMPOK PENGGUNA AIR BERSIH DESA PAKEL MELALUI TEKNOLOGI FILTER BETON PASIR
}

\author{
Zulis Erwanto ${ }^{1}$, Wahyu Naris Wari' ${ }^{2}$, Yuni Ulfiyati ${ }^{3}$ \\ Program Studi Teknik Sipil, Politeknik Negeri Banyuwangi \\ Jl. Raya Jember Km. 13, Labanasem, Kabat, Banyuwangi \\ 1zulis.poliwangi@gmail.com \\ 2naris.civilengineer@gmail.com \\ 3yuni_ulfia@yahoo.co.id
}

\begin{abstract}
ABSTRAK
Desa Pakel, Kabupaten Banyuwangi mengalami permasalahan dalam pemenuhan kebutuhan air bersih bagi warganya. Sumber mata air utama yang digunakan oleh warga Desa Pakel terletak di daerah perbukitan dengan konstruksi bangunan penangkap mata air yang sederhana. Lokasi mata air berada di tengah hutan dan terletak di kemiringan bukit menyebabkan air yang tertampung berpeluang mengalami pencemaran dan kandungan sedimen yang tinggi apalagi pada saat musim penghujan. Mitra dalam kegiatan IbM adalah Pengelola kelompok pengguna air minum Desa Pakel Kabupaten Banyuwangi.

Sesuai prioritas kebutuhan maka ditawarkan solusi permasalahan yang dihadapi Mitra yakni dengan penyuluhan tentang teknologi penjernihan dan pengolahan air bersih, dan rancang bangun instalasi filter beton pasir. Manfaat yang diperoleh berupa pemahaman tentang pentingnya kesehatan dalam pengolahan air bersih dengan sistem instalasi pengolahan air bersih menggunakan teknologi filter beton pasir.

Berdasarkan hasil sosialisasi dan penyuluhan pengolahan air bersih di Desa Pakel tanggal 24 September 2016 di Balai Desa Pakel, pengolahan air bersih dalam upaya pemenuhan kebutuhan air bersih melalui proses penjernihan air dengan instalasi teknologi filter beton pasir yang ditempatkan di dalam reservat. Filter beton pasir merupakan salah satu unit proses dalam instalasi pengolahan air (IPA) yang terbuat dari bahan dari kerikil, pasir beton, arang aktif, dan mortar pasir silica dengan perbandingan 1 PC : 10 PS yang disusun sedemikian rupa untuk menghilangkan kekeruhan air. Berhubung instalasi penempatan filter tersebut di dalam tandon dengan tekanan kecil maka filter beton pasir yang digunakan menggunakan ukuran partikel lebih dari 1-2 mm dengan ketebalan $15 \mathrm{~cm}$ agar kuantitas debit airnya tetap sesuai dengan kapasitasnya dan sirkulasinya biar cepat. Bahan yang digunakan sebagai filter terbuat dari pipa PVC $\emptyset$ 4" dengan ketinggian $50 \mathrm{~cm}$ menyesuaikan diameter pipa outlet. Filter terdiri dari 4 tabung pipa. Teknologi filter beton pasir ini merupakan bentuk prototype filter untuk percontohan di Desa Pakel dan bisa dibuat skala rumah tangga di tiap-tiap rumah atau diinstalasi sebelum masuk ke hidran umum.
\end{abstract}

Keywords- Air Bersih, Beton Pasir, Filter, Instalasi, Reservoar

\section{PENDAHULUAN}

Desa Pakel merupakan salah satu desa di Kabupaten Banyuwangi yang mengalami permasalahan dalam pemenuhan kebutuhan air bersih bagi warganya. Sumber mata air utama yang digunakan oleh warga Desa Pakel terletak di daerah perbukitan dengan konstruksi bangunan penangkap mata air yang sederhana. Lokasi mata air berada di tengah hutan dan terletak di kemiringan bukit menyebabkan air yang tertampung berpeluang mengalami pencemaran dan kandungan sedimen yang tinggi apalagi pada saat musim penghujan. Pendistribusian air dari sumber mata air utama dilakukan dengan menggunakan tandon penampung dan air langsung didistribusikan ke rumah-rumah warga di desa tersebut. Air baku yang diambil warnanya keruh pada saat musim penghujan karena tidak ada proses penjernihan sebelum air tersebut didistribusikan.

Nilai residu tersuspensi mempengaruhi kekeruhan air, sehingga mengakibatkan nilai COD yang tinggi, dan secara langsung akan meningkatkan nilai bakteri yang terkandung pada air tersebut. Perlu pengolahan kualitas air baku karena prosesnya masih sederhana karena dana yang dipungut dari warga untuk 
pembiayaan dalam pengelolaan air bersih juga masih minim. Belum ada upaya dan teknologi yang diterapkan untuk meningkatkan kualitas air bersih agar bisa memenuhi kebutuhan air bersih di Desa Pakel.

Pada umumnya air baku yang digunakan tanpa diolah terlebih dahulu akan menimbulkan dampak buruk bagi kesehatan manusia, karena itu sangat penting dilakukan penjernihan air agar didapatkan air bersih yang layak bagi masyarakat Desa Pakel. Mitra dalam kegiatan IbM ini adalah Pengelola kelompok pengguna air minum Desa Pakel Kabupaten Banyuwangi.

\section{TARGET DAN LUARAN}

Dari berbagai masalah yang dihadapi oleh Mitra IbM tersebut maka solusi yang ditawarkan adalah pengolahan air bersih dalam upaya pemenuhan kebutuhan air bersih layak konsumsi melalui proses penjernihan air sebelum air tersebut didistribusikan. Oleh sebab itu sesuai dengan prioritas kebutuhan maka ditawarkan solusi terhadap permasalahan yang dihadapi Mitra IbM yakni dengan penyuluhan tentang teknologi penjernihan dan pengolahan air bersih, rancang bangun instalasi pengolahan air bersih dengan teknologi filter beton untuk penjernih air. Untuk keberlanjutan kegiatan ini maka dibentuk struktur organisasi pengelola kelompok pengguna air minum Desa Pakel untuk manajemen dan pemeliharaan instalasi air bersih tersebut.

Tabel I. Rencana Target Capaian Luaran

\begin{tabular}{|c|c|c|}
\hline No & Jenis Luaran & $\begin{array}{c}\text { Indikator } \\
\text { Capaian }\end{array}$ \\
\hline 1 & $\begin{array}{l}\text { Publikasi ilmiah di } \\
\text { jurnal/prosiding }\end{array}$ & Submitted \\
\hline 2 & $\begin{array}{l}\text { Publikasi pada media massa } \\
\text { (cetak/elektronik) }\end{array}$ & Sudah terbit \\
\hline 3 & $\begin{array}{l}\text { Peningkatan omzet pada mitra } \\
\text { yang bergerak dalam bidang } \\
\text { ekonomi }\end{array}$ & Tidak ada \\
\hline 4 & $\begin{array}{l}\text { Peningkatan kuantitas dan } \\
\text { kualitas produk }\end{array}$ & Tidak ada \\
\hline 5 & $\begin{array}{l}\text { Peningkatan pemahaman dan } \\
\text { keterampilan masyarakat }\end{array}$ & Ada \\
\hline 6 & $\begin{array}{l}\text { Peningkatan } \\
\text { ketentraman/kesehatan } \\
\text { masyarakat (mitra masyarakat } \\
\text { umum) }\end{array}$ & Ada \\
\hline 7 & $\begin{array}{l}\text { Jasa, model, rekayasa sosial, } \\
\text { sistem, produk/barang }\end{array}$ & Produk \\
\hline 8 & $\begin{array}{l}\text { Hak kekayaan intelektual } \\
\text { (paten, paten sederhana, hak } \\
\text { cipta, merek dagang, rahasia } \\
\text { dagang, desain produk industri, } \\
\text { perlindungan varietas tanaman, } \\
\text { perlindungan topografi. }\end{array}$ & Tidak ada \\
\hline 9 & Buku Ajar & Tidak ada \\
\hline
\end{tabular}

Sumber : Hasil Analisis, 2016

\section{METODE PELAKSANAAN}

Dalam pelaksanaan program ini, metode pelaksanaan yang digunakan didasari dari permasalahan yang ada di Desa Pakel yaitu mengatasi permasalahan kebutuhan air bersih melalui proses pengolahan menggunakan filter beton pasir melalui beberapa tahapan yaitu:

a. Kegiatan Sosialisasi kegiatan pengabdian kepada masyarakat

b. Kegiatan Penyuluhan dan Pelatihan Pengolahan Air Bersih

c. Kegiatan Pelatihan Instalasi dan Pembuatan Filter Beton Pasir

d. Monitoring dan Evaluasi Indikator Keberhasilan Program

e. Publikasi

f. Pelaporan Akhir

Kegiatan ini difokuskan pada proses filtrasi. Proses ini dimaksudkan untuk menyaring zat padat tersuspensi yang tertinggal dalam air jernih dengan mengunakan bahan yang bisa dilewati oleh air namun bisa menghentikan kotoran yang masih tertinggal di air, seperti jala berukuran mikro. Filter beton pasir merupakan salah satu unit proses dalam instalasi pengolahan air (IPA). Filter ini cukup handal menghilangkan kekeruhan air dan sebagai bagian dari unit proses pengolahan air dalam sistem penyediaan air minum. Bentuk desain dan proses filtrasi dapat dilihat pada sketsa Gambar I.

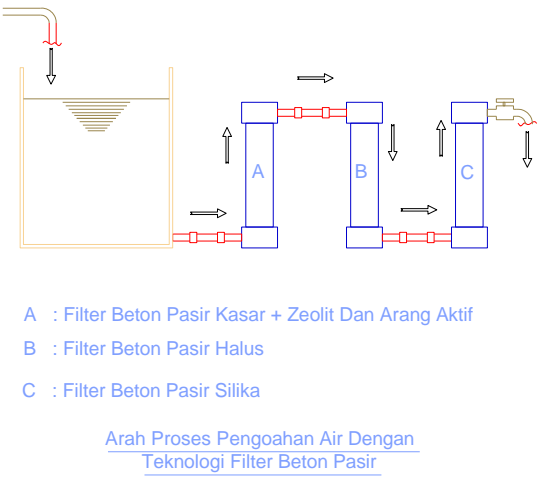

Gambar I. Gambar Desain Proses Pengolahan Air (Hasil Desain, 2016)

\section{KELAYAKAN PERGURUAN TINGGI}

Unit P3M (Pusat Penelitian Dan Pengabdian Kepada Masyarakat) Politeknik Negeri Banyuwangi khususnya telah beberapa kali ikut berperan aktif dalam program pengabdian kepada masyarakat seperti terlihat pada Tabel II. berikut.

Tabel II. Inventarisasi Program Pengabdian Kepada Masyarakat Politeknik Negeri Banyuwangi 


\begin{tabular}{|c|c|c|c|}
\hline \multirow{2}{*}{ Tahun } & \multirow{2}{*}{ Judul Pengabdian Kepada Masyarakat } & \multicolumn{2}{|c|}{ Pendanaan } \\
\hline & & Sumber & Jml (Juta Rp \\
\hline 2012 & Pelatihan Kerja Batu untuk Mandor & APBN & $\operatorname{Rp} \quad 10.00$ \\
\hline 2012 & Pelatihan Program Software Teknik Sipil untuk SMA/SMK & APBN & $\operatorname{Rp} 10.00$ \\
\hline 2012 & Pelatihan Software Teknik Sipil untuk Pemuda Karang Taruna Rogojampi & APBN & $\operatorname{Rp} 10.00$ \\
\hline 2012 & $\begin{array}{l}\text { Pelatihan Microsoft Office Bagi Tenaga Pengajar Di SDN } 01 \text { Pakel Kecamatan Licin } \\
\text { Banyuwangi }\end{array}$ & APBN & 10.00 \\
\hline 2012 & Sertifikikasi Tenaga Konstruksi Di Banyuwangi & APBN & $\operatorname{Rp} 10.00$ \\
\hline 2012 & Penyuluhan Infrastruktur Yang Baik Di Daerah Pesisir & APBN & $\operatorname{Rp} 15.00$ \\
\hline 2012 & Kontrol Frekuensi dan Tegangan Untuk Pembangkit Listrik & APBN & $\operatorname{Rp} 15.00$ \\
\hline 2012 & Pembinaan Penggunaan Sistem Informasi Perpustakaan SMA/SMK Di banyuwangi & APBN & 15.00 \\
\hline 2012 & $\begin{array}{l}\text { Peningkatan Kemampuan Perangkat desa Dalam Pengoperasian Aplikasi Perkantoran di } \\
\text { Kecamatan Kabat }\end{array}$ & APBN & $\operatorname{Rp} 15.00$ \\
\hline 2012 & Pembinaan Penggunaan Sistem Informasi Perencanaan Keuangan Tingkat Kecamatan & APBN & $\operatorname{Rp} 15.00$ \\
\hline 2012 & $\begin{array}{l}\text { Pelatihan Microsofft Office Bagi Perangkat Desa Se-Kecamatan Wongsorejo Guna } \\
\text { Meningkatkan Kualitas Pelayanan Terhadap Masyarakat }\end{array}$ & APBN & Rp 15.00 \\
\hline 2012 & $\begin{array}{l}\text { Peningkatan Kemampuan Guru Sekolah Dasar di Kecamatan Wongsorejo dalam } \\
\text { Mengoperasikan Komputer }\end{array}$ & APBN & Rp 15.00 \\
\hline 2012 & $\begin{array}{l}\text { Pengembangan Lembar Kerja Siswa (LKS) Bilingual Pokok Bahasan Statistika dan Peluang } \\
\text { Pada KelasXI SMA/MA }\end{array}$ & APBD & $\operatorname{Rp} 10.00$ \\
\hline 2012 & Pelathan Pengelasan Bagi Karang Taruna Masyarakat Banyuwangi & APBN & 15.00 \\
\hline 2012 & Rancang Bangun Mesin Pengering Bulir Jagung Untuk Bahan Baku Marning & APBN & $\operatorname{Rp} 15.00$ \\
\hline 2013 & Instalasi Biogas Menggunakan Substrat Limbah & DIKTI & $\operatorname{Rp} 49.00$ \\
\hline 2013 & $\begin{array}{l}\text { IbM UKM Pembuat Tahu di Desa Sumberberas dalam Peningkatan Produktifitias Melalui } \\
\text { Penggunaan Mesin Penyaring dan Pemeras Bubur Kedelai }\end{array}$ & DIKTI & $\operatorname{Rp} \quad 45.00$ \\
\hline 2015 & $\begin{array}{l}\text { Program Hibah Bina Desa Pengembangan Infrastruktur Pariwisata Air Terjun Selendang } \\
\text { Arum Desa Sumber Arum Kecamatan Songgon }\end{array}$ & RISTEKDIKTI & I $\operatorname{Rp} 40.00$ \\
\hline 2016 & IbM Kelurahan Sobo dalam Pemberdayaan Ibu-bu rumah Tangga Non Produktif & RISTEKDIKTI & 38.00 \\
\hline 2016 & $\begin{array}{l}\text { IbM Desa Purwodadi Kecamatan Gambiran Melalui Rancang Bangun Pembangkit Listrik } \\
\text { Tenaga Matahari (PLTM) Sebagai Upaya Peningkatan Frekuensi Produksi Hasil Panen } \\
\text { Tanaman Buah Naga Merah }\end{array}$ & RISTEKDIKTI & I $\operatorname{Rp} \quad 32.50$ \\
\hline 2016 & Pelatihan Teknologi Konstruksi Paving dalam Mengembangkan Kawasan Desa Labanasem & PNBP & 10.00 \\
\hline 2016 & $\begin{array}{l}\text { Pembuatan Media Pembelajaran Berbasis Teknologi Informasi untuk Anak Berkebutuhan } \\
\text { Khuusus Tunaganda dan Autis di Kabupaten Banyuwangi }\end{array}$ & PNBP & $\operatorname{Rp} 10.00$ \\
\hline
\end{tabular}

\section{HASIL DAN LUARAN YANG DICAPAI}

Untuk perencanaan instalasi pengolahan air bersih di Desa Pakel perlu di lihat terlebih dahulu kondisi eksisting di lapangan lokasi sumber mata air yang digunakan untuk mengetahui penyebab permasalahan yang terjadi.

Lokasi sumber mata air yang digunakan penduduk Desa Pakel terletak di daerah perbukitan atau dataran tinggi di sekitar daearah perkebunan. Kondisi jaringan pipa distribusi dari sumber air ke penduduk rata-rata masih menggunakan pipa berbahan PVC, dan ada juga yang sudah menggunakan pipa besi pada sumber - sumber yang lain. Pengelolaan air bersih di Desa Pakel pada dasarnya dikelola oleh HIPAM di setiap Dusun masing-masing. Jadi setiap dusun di Desa Pakel sudah memiliki tandon air bersih sendiri-sendiri.

Dengan adanya bentuk pengelolaan HIPAM yang dikelola oleh masing-masing Dusun, perlu adanya bentuk koordinasi yang baik agar pengelolaan air bersih bisa terpadu dan bersinergi dalam hal pengelolaan dan perbaikan fasilitas sarana prasarana air bersih di masingmasing Dusun Desa Pakel.

Sumber mata air utama yang digunakan oleh warga Desa Pakel terletak di daerah perbukitan dengan konstruksi bangunan penangkap mata air yang sederhana. Lokasi mata air berada ditengah hutan dan terletak dikemiringan bukit menyebabkan air yang tertampung berpeluang mengalami pencemaran dan kandungan sedimen yang tinggi apalagi pada saat musim penghujan.

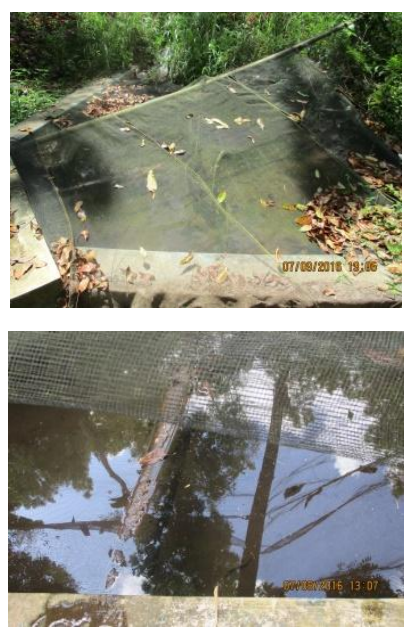

(a)

(b)

Gambar II. (a) Konstruksi Bangunan Penangkap Sumber Mata Air;

(b) Kondisi Tangkapan Air Yang Sudah Penuh Sedimen (Dok, 2016)

Permasalahan utama penyebab kekeruhan saat musim penghujan adalah akibat kesalahan desain konstruksi bangunan penangkap airnya. Untuk lokasi sumber air di daerah perbukitan dengan jenis sumber air dari patahan lapisan batuan disarankan menggunakan jenis konstruksi bangunan penangkap mata air reservoir di tempat.

Tipe yang paling cocok digunakan adalah tipe kombinasi bendung dengan reservoir. Sebelum air masuk ke reservoir, perlu adanya pembendungan terlebih dahulu agar sedimen bisa tertahan sementara di bendung dengan dilengkapi pintu intake atau pintu pengambilan air masuk ke pipa reservoir.

Sumber mata air di Desa Pakel berpusat di bukit Dusun Taman Glugo dengan letak koordinat 080 11' 06,1" LS dan 1140 12' 41.2" BT dengan elevasi $590 \mathrm{~m} \mathrm{dpl}$.

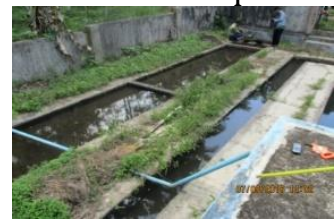

(a)

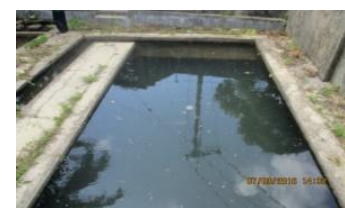

(b)
Gambar III. (a) Kondisi Bangunan Koagulasi Reservoar Terminal;

(b) Kondisi Bangunan Pengendapan (Dok, 2016)

Pusat pertemuan sumber air terletak pada reservoir terminal seperti pada Gambar IV. reservoir terminal tersebut masih sederhana 
dengan fasilitas tambahan seperti adanya jalur koagulasi untuk proses pengendapan sedimen secara lambat sebelum masuk ke bak sedimentasi.

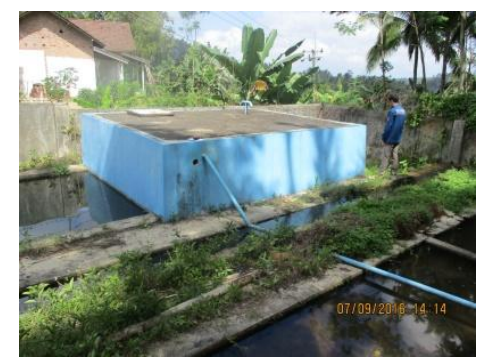

Gambar IV. Kondisi Bangunan Reservoar Terminal (Dok, 2016)

Kondisi bangunan reservoar terminal saat ini tidak terawat, dan sudah banyak kandungan lumpur di dalam reservoarnya. Lokasi reservoar terminal terletak di koordinat 080 11' 31.5" LS dan 1140 13' 23.4" BT dengan elevasi $562 \mathrm{~m} \mathrm{dpl}$. Beda tinggi dengan lokasi sumber airnya adalah sebesar $28 \mathrm{~m}$ dpl.

Sesuai prioritas kebutuhan terhadap permasalahan di lapangan maka ditawarkan solusi yang dihadapi Mitra IbM yakni dengan penyuluhan tentang teknologi penjernihan dan pengolahan air bersih, dan rancang bangun instalasi filter beton pasir. Manfaat yang diperoleh berupa pemahaman tentang pentingnya kesehatan dalam pengolahan air bersih dengan sistem instalasi pengolahan air bersih menggunakan teknologi filter beton pasir. Rencana luaran berupa produk desain dan instalasi air bersih dengan menggunakan teknologi filter beton pasir.

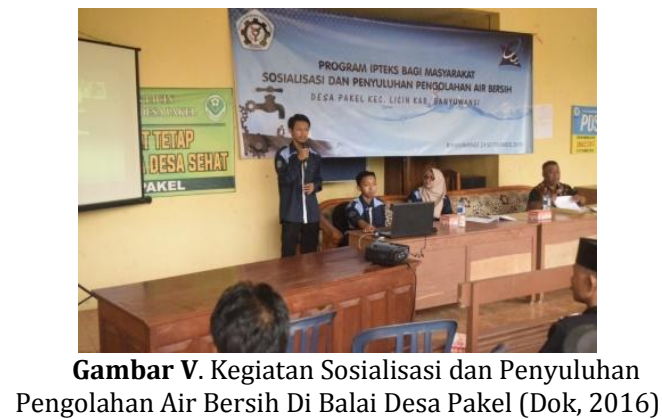

Berdasarkan hasil sosialisasi dan penyuluhan pengolahan air bersih di Desa Pakel tanggal 24 September 2016 di Balai Desa Pakel, pengolahan air bersih dalam upaya pemenuhan kebutuhan air bersih melalui proses penjernihan air dengan instalasi teknologi filter beton pasir yang ditempatkan di dalam reservoar (tandon) terminal air bersih. Filter beton pasir merupakan salah satu unit proses dalam instalasi pengolahan air (IPA) yang terbuat dari bahan dari kerikil, pasir beton, arang aktif, dan mortar pasir silica dengan perbandingan 1 PC : 10 PS yang disusun sedemikian rupa untuk menghilangkan kekeruhan air. Konsep yang digunakan adalah kombinasi Down Flow dan Up Flow.

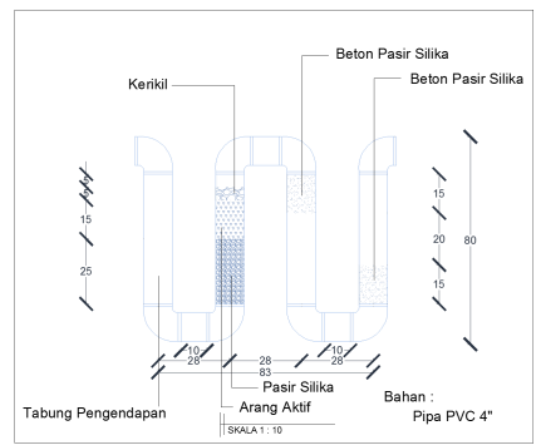

Gambar VI. Desain Instalasi Filter Beton Pasir (Dok, 2016)

Berhubung instalasi penempatan filter tersebut di dalam tandon dengan tekanan kecil maka filter beton pasir yang digunakan menggunakan ukuran partikel lebih dari 1-2 mm dengan ketebalan $15 \mathrm{~cm}$ agar kuantitas debit airnya tetap sesuai dengan kapasitasnya dan sirkulasinya biar bisa cepat. Bahan yang digunakan sebagai filter terbuat dari pipa PVC $\varnothing$ 4" dengan ketinggian $50 \mathrm{~cm}$ menyesuaikan diameter pipa outlet.

Filter terdiri dari 4 tabung pipa. Tabung pertama berisi filter beton pasir silica down flow, tabung kedua berisi filter beton pasir silica up flow, tabung ketiga berisi bahan pasir, arang aktif yang berasal dari arang batok kelapa, dan kerikil, sedangkan tabung keempat merupakan pipa kosong sebagai tempat pengendapan sebelum masuk ke pipa outlet tandon.

Dengan bekal konsep ini maka perlu adanya trial dan simulasi prototype filter beton pasir tersebut sebelum dipasang di lokasi tandon terminal Desa Pakel.

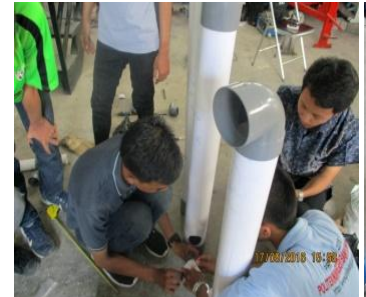

(a)

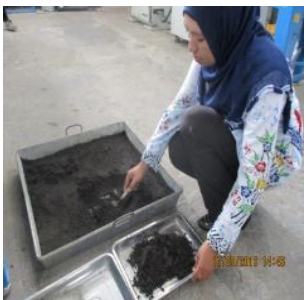

(b)
Gambar VII. (a) Pembuatan Trial Instalasi Pipa Filter; (b) Proses Pembuatan Filter Beton Pasir (Dok, 2016)

Dalam pembuatan trial filter beton pasir, perlu dipersiapkan bahan atau materialnya, seperti pasir, kerikil, arang aktif yang terbuat dari arang 
batok kelapa, pasir silica, pipa PVC beserta sambungannya.

Setelah trial di Laboratorium Program Studi Teknik Sipil Politeknik Negeri Banyuuwangi, maka siap untuk diaplikasikan di lapangan pada tanggal 1 Oktober 2016 tepatnya pada reservoir terminal air bersih di Desa Pakel.

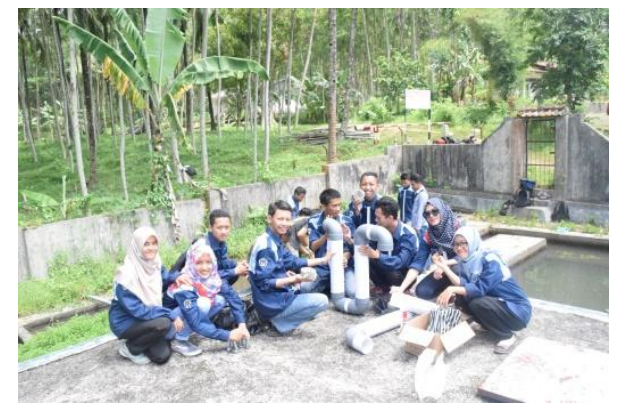

Gambar VIII. Perakitan Instalasi Pipa Filter Beton Pasir di Reservoar Terminal Desa Pakel (Dok, 2016)

Teknologi filter beton pasir ini merupakan bentuk prototype filter untuk percontohan di Desa Pakel dan bisa dibuat skala rumah tangga di tiap-tiap rumah atau diinstalasi sebelum masuk ke hidran umum. Diharapkan dengan adanya penerapan filter beton pasir warga Desa Pakel dapat meningkatkan kualitas air bersih. Khusus bagi pengurus HIPAM tiap-tiap Dusun di Desa Pakel diharapkan mampu merawat instalasi pengelolaan air bersih di reservoir dan mengelola secara swadaya dalam penggunaan kebutuhan air bersih secara berkelanjutan.

\section{KESIMPULAN DAN SARAN}

1. Berdasarkan hasil sosialisasi dan penyuluhan pengolahan air bersih di Desa Pakel tanggal 24 September 2016 di Balai Desa Pakel, pengolahan air bersih dalam upaya pemenuhan kebutuhan air bersih melalui proses penjernihan air dengan instalasi teknologi filter beton pasir yang ditempatkan di dalam reservoar (tandon) terminal air bersih. Filter beton pasir merupakan salah satu unit proses dalam instalasi pengolahan air (IPA) yang terbuat dari bahan dari kerikil, pasir beton, arang aktif, dan mortar pasir silica dengan perbandingan 1 PC : 10 PS yang disusun sedemikian rupa untuk menghilangkan kekeruhan air. Konsep yang digunakan adalah kombinasi Down Flow dan Up Flow.

2. Filter beton pasir yang digunakan menggunakan ukuran partikel lebih dari 1-2 mm dengan ketebalan $15 \mathrm{~cm}$. Bahan yang digunakan sebagai filter terbuat dari pipa PVC $\emptyset$ 4" dengan ketinggian $50 \mathrm{~cm}$ menyesuaikan diameter pipa outlet. Filter terdiri dari 4 tabung pipa. Tabung pertama berisi filter beton pasir silica down flow, tabung kedua berisi filter beton pasir silica up flow, tabung ketiga berisi bahan pasir, arang aktif yang berasal dari arang batok kelapa, dan kerikil, sedangkan tabung keempat merupakan pipa kosong sebagai tempat pengendapan sebelum masuk ke pipa outlet tandon.

3. Luaran yang dicapai adalah peningkatan pemahaman pengguna air bersih dan pengurus HIPAM tentang pentingnya pengelolaan air bersih dan kualitas air bersih. Selain itu juga publikasi melalui jurnal/prosiding dan media cetak dan menghasilkan produk prototype filter beton pasir yang telah diterapkan di reservoir terminal (tandon) air bersih di Desa Pakel.

Beberapa saran dalam pengolahan air bersih di Desa Pakel antara lain :

1. Perlu adanya rekonstruksi desain bangunan penangkap mata air, agar sesuai dengan kondisi medan dan hidrologi di Desa Pakel.

2. Perlu adanya kegiatan penyuluhan atau pelatihan tentang pengelolaan penggunaan dan distribusi air bersih pada kelompok pengguna air bersih atau pada pengurus HIPAM di tiap-tiap dusun di Desa Pakel.

3. Perlu dikembangkan teknologi filter beton pasir untuk skala rumah tangga atau pada hidran umum.

4. Perlu pemeliharaan fasilitas sarana dan prasarana air bersih secara rutin agar bisa selalu terpelihara dan terawat dengan baik.

\section{UCAPAN TERIMA KASIH}

Terima kasih sebesar-besarnya kepada Direktorat Riset dan Pengabdian Masyarakat, Direktorat Jenderal Penguatan Riset Dan Pengembangan, Kementerian Riset, Teknologi, Dan Pendidikan Tinggi atas pendanaan dan kepercayaannya yang diberikan agar bisa terlaksananya kegiatan pengabdian kepada masyarakat ini, kedua kalinya kepada Direktur dan Wakil Direktur 1, 2, dan 3 Politeknik Negeri Banyuwangi atas dukungan dan fasilitasnya yang telah diberikan, serta anggota pengabdi khususnya dan civitas akademika Politeknik Negeri Banyuwangi pada umumnya atas kerjasamanya selama ini.

\section{DAFTAR PUSTAKa}

[1] Baruth E.E (Technical Editor), 2005, Water Treatment Plant Desain, AWWA \& ASCE, 4th edition, McGraw-Hill, Inc., Newyork.

[2] Crittenden, J., Trussel, R. R., Hand, D. W., Howe, K. J., and Tchobanoglous, G., 2005, Water Treatment.: 
Principles and Desain, 2nd edition, John Wiley \& Sons, Inc., Newyork.

[3] Huang J. Y. C. and Basagoiti, J., 1989, Effect of Solid Property on Rates of Solid Disloggement, J. Environmental Engineering, ASCE, Vol.115 No.1.ISSN. 0733-9372.

[4] Kamulyan, B., Nurrochmad, F., Triatmadja, R., and Sunjoto, 2009, Capacity of Concrete Sand Filter to Treat High Turbid Water, disajikan pada konferensi internasional Sustainable Development for Water and Waste Water Treatment, 14-15 Desember 2009, Yogyakarta.

[5] Kamulyan, B., Nurrochmad, F., Triatmadja, R., and Sunjoto, 2011, The Head Loss Development and Turbidity Removal of The Filtration using Concrete Sand Filter With Various Cement to Sand Ratio, disajikan pada konferensi internasional Enviromental Pollution and Public Health - iCCBEE, 17-20 May 2012, Yogyakarta.

[6] Triatmadja, R., 2008, Kajian Awal Prospek Filter Beton Pasir Sebagai Teknologi Tepat Filtrasi Air Bersih, disajikan pada Seminar Nasional Teknologi Tepat Guna Penanganan Sarana Prasarana di Indonesia, Yogyakarta. 